POLLACK PERIODICA

An International Journal for Engineering and Information Sciences

DOI: $10.1556 / 606.2018 .13 .1 .14$

Vol. 13, No. 1, pp. 157-168 (2018)

www.akademiai.com

\title{
PRIZREN - REVITALIZING THE HISTORIC WATER CHANNEL SYSTEM FOR MODERN CITY LIFE
}

\author{
${ }^{1}$ Besa JAGXHIU, ${ }^{2}$ Krisztián KOVÁCS-ANDOR \\ ${ }^{1}$ Higher Education Institution, University for Business and Technology, Lagja Kalabria \\ nn 10000, Prishtina, Kosovo, e-mail: besa.jagxhiu@ubt-uni.net \\ ${ }^{2}$ Faculty of Engineering and Information Technology, University of Pécs, Boszorkany u. 2 \\ H-7624 Pécs, Hungary, e-mail: kovacs.andor.k@gmail.com
}

Received 1 January 2017; accepted 30 August 2017

\begin{abstract}
The city of Prizren is one of the oldest settlements in Kosovo and in the Eastern Europe, located in the middle of the ancient Venice-Istanbul trading route, which has always been a crossroad of trade and culture for the whole region. It used to be called 'Venice of Balkans' thanks to its sophisticated system of channels that used to have, so-called 'Jaze', which were branched from the river and were scattered throughout the neighborhoods of the city, and further the channels were branched into smaller channels, which have carried water through small public streets to each house in Prizren.

The aim of this research is to identify the role, function and value of this channels system in the city life of Prizren, and whether these channels can be functionalized and restored for the today's needs. This research attempts to present the social, economic, spatial and environmental values of the revitalization of this channels system in the city of Prizren and the importance of its restoration and integration into today's modern life.
\end{abstract}

Keywords: Revitalization, Prizren, system of channels, 'Jaze', Restoration, Integration

\section{Introduction}

The idea of revitalization is to balance the current rapid development in urban areas through conserving urban identity, culture and traditions. Furthermore, the revitalization program can create job opportunity to increase peoples' income, preserve natural recourses, provides suitable urban amenities and facilities for the users [1].

Revitalization means to give new life, vigor, vitality to an area. It means applying good urban design principles, understandings and disciplines to bring fresh vitality to an area, preserving and re-using that, which is treasured by the local community, adding 
new assets, intertwining economic and social and environmental considerations to create great places, and working together to create a vision, a plan of implementation actions, and sufficient resources, commitment and goodwill to carry out the plan for the area [2]. With urban revitalization can be improved the physical, economic, social, and environmental state of an urban area.

Cities are in a continuous process of change and readjustment of their different parts, which are spontaneously developed or deliberately planned under different socioeconomic, natural and political conditions indifferent periods [3]. Historic cities are host to exciting historical sites, outstanding heritage buildings, and unique local cultures: these represents a country and can be a sourse of pride [4]. Meanwhile, human provide actions to maintain the city identity in order to sustain and keep alive the city especially the old fabric that infill development [5].

Urban fabric reflects the morphological composition of physical elements within a certain area [6]. The urban fabric of the historic cities has formed in a time process and today it has been surrounded by the current technologies and urban development. Although in their past these fabrics had been hierarchical and logical functions, today, in terms of structural and functional cases it has deficiencies and cannot meet the needs of today's life. Therefore, based on one of the requirements in the city and contemporary urbanization is rehabilitating the urban fabrics [7].

The historic urban fabric is the subset of the modern city and takes advantage of special features in the city in which by passing the time some values were stored and by revealing them at any time forms a historic aspect. Theses fabrics remained from the past reflect the historic and cultural of the city obtained from the interaction between human and the surrounding environment during the history and most of them in spite of their value are being damaged [7]. 'Green' has become a way of life. Thinking green and sustainable means also trying to preserve what is given, what is present and trying to make the best of it [8]. Striving to provide sustainable solutions the three main pillars of sustainability (social, economic and environmental dimension) should be included in the objective functions [9].

\section{Background}

The Municipality of Prizren is located in the southern part of Kosovo. It consists of an area of $640 \mathrm{~km}^{2}$; with a population of around 178,000, while the city of Prizren has around 110,000 inhabitants, making it the second largest city in Kosovo. Prizren is located on the banks of the river Bistrica, on the slopes of the Sar Mountains and on the border with Albania and Macedonia [10] (see Fig. 1).

The city of Prizren is one of the oldest settlements in Kosovo and in the Eastern Europe, located in the middle of the ancient Venice-Istanbul trading route, which has always been a crossroad of trade and culture for the whole region, and ethnic cultures, which lived next to each other, as were: Dardanian-Illyrian-Albanian, Roman, Byzantine, Serb, Turkish-Ottoman, etc. In the city of Prizren various official languages were spoken during the centuries. The cultural heritage of Prizren reflects the wonderful history of a city with a culture that stretches throughout the centuries up to the present day [11]. Prizren has an ethnically diverse population composed of mainly Albanians, 
and the rest are ethnic minorities: Bosnians, Turks, Roma, Serbian, Ashkali and others [10]. Although Bosnians are the main minority group in terms of numbers, the Kosovo Turkish community is socially prominent and influential. In the city, the Turkish language is widely spoken, also among Albanians [11] (Fig. 2 and Fig. 3).

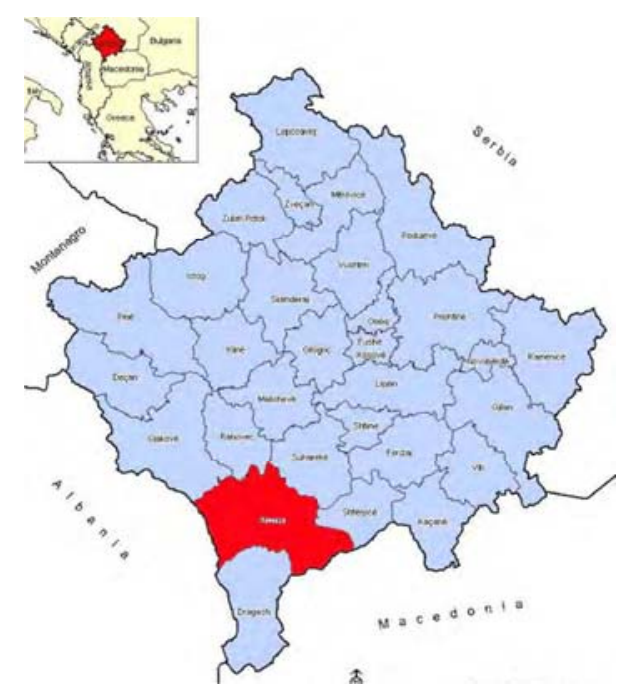

Fig. 1. Prizren in Kosovo Map, 2007, [12]

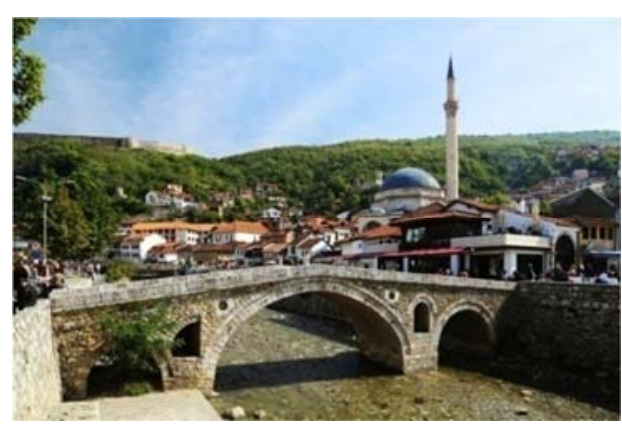

Fig. 2. View towards the Stone Bridge, Sinan Pasha Mosque and in the background the Castle of the city, [13]

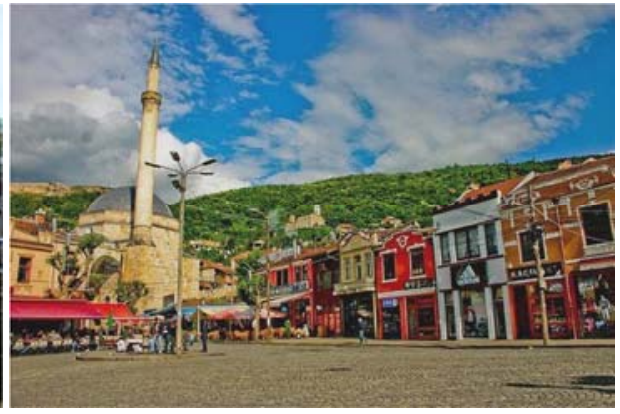

Fig. 3. Main Square of the city with the fountain, Shadervan in the middle, in the background the Sinan Pasha Mosque, [14]

Looking back at the history of the city of Prizren, it is obvious that it has been the richest city with water in Kosovo during all the time. One of the most important features of Prizren as a settlement is the river Bistrica that passes in the middle of it (see Fig. 4). Looking at the historical development of Prizren, it can be seen that the city was spread and developed around the river. The clean and rapidly flowing water from the river except from the keeping the city clean, it was one of the most important factors in the development of the city [15]. 


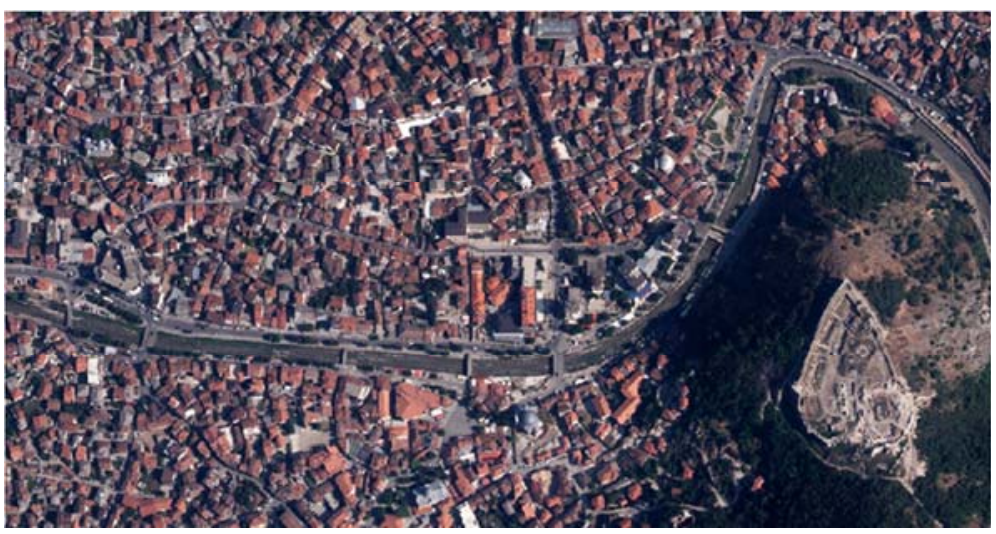

Fig. 4. River Bistrica passes in the middle of the city of Prizren [16]

Prizen was used to be called 'Venice of Balkans' thanks to its sophisticated unique system of water channels that used to have, so-called 'Jaze', which were branched from the river and were scattered throughout the neighborhoods of the city. Furthermore, the channels were branched into smaller channels, which have carried water through small public streets to every house in Prizren (Fig. 5 - Fig. 7).

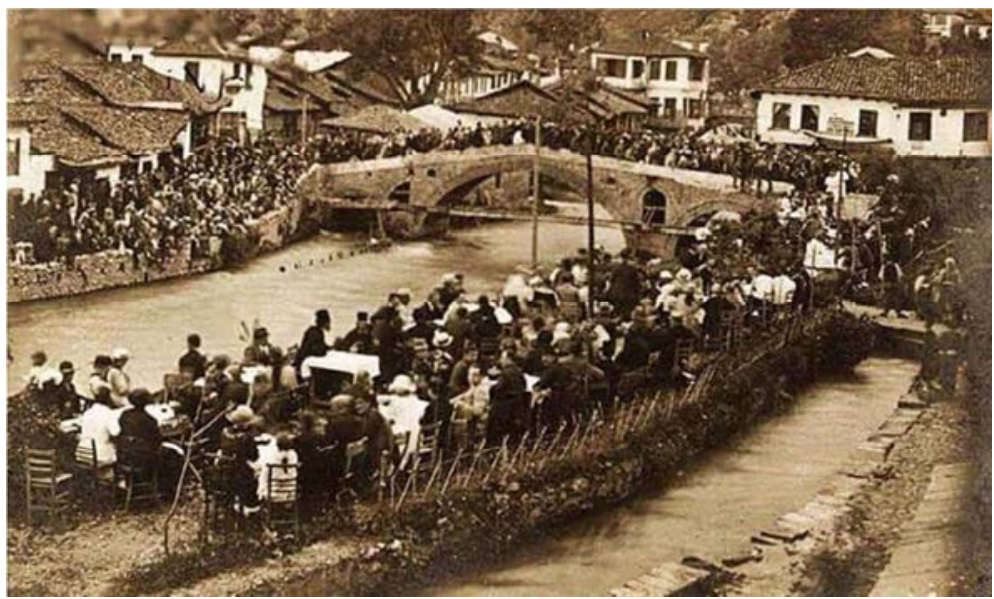

Fig. 5. Main 'Jaz' branched from the river Bistrica, [17]

In Fig. 5 the main channel next to the river Bistrica is presented, which is branched from the river, and as it is presented in the picture there were held many social activities and it played a very important role in the social life of the city. In Fig. 6 a smaller channel in the public street can be seen, which is branched from the main channel and from there again the smaller channels so called 'potok' were branched into every house, carrying water to every house of the city, as it can be seen in Fig. 7. 


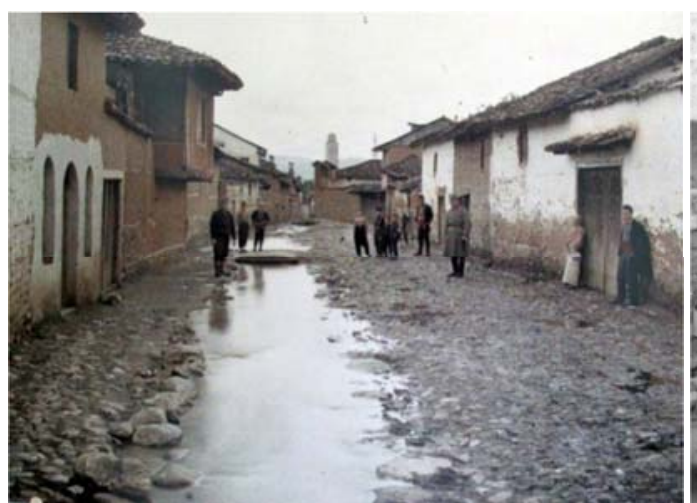

Fig. 6. 'Jaz' in public street, Albert Kahn 1913, [18]

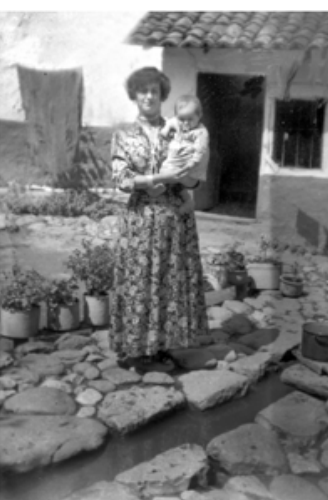

Fig. 7. 'Potok' inside the garden of a house, [15]

The aim of this research is to identify the role, function, and value of this unique water channels system in the city life of Prizren, and whether these channels can be functionalized and restored for the today's needs.

This research will try to answer the following research questions:

1. What was the role, function and value of water channels system in the city life of Prizren?

2. Which shapes and sizes have characterized water channels system and their urban infrastructure functional scheme?

3. Is it possible to revitalize these channels for the use of today's needs? Is it worth, can the city and the citizens benefit from this?

\section{Analysis of the role, function and value of the channels system}

This system of channels through water connected neighborhoods to neighborhoods, gardens to gardens, neighbors to neighbors, and so connected the city with the environment, Fig. 8. At the exit of the city all the channels were back together and returned to the riverbed, as it is presented in Fig. 9 - Fig. 10. These channels created a unique urban area where the inhabitants have lived together in harmony with the environment. Water that has been part of each unit of the city was very clean and drinkable, and with time it become magical for the visitors of the city, therefore they started to call Prizren 'Venice' of Balkans.

Every citizen cared for the river and the water channels that flowed from the river, even the small children were educated not to throw anything or spin in the channels or in the river. There was an old saying that if you spin into the river or channels, something bad will happen to you, and so you will become blind, or you will become mentally ill, and in this way they saved the water and it remained clean every time, at every point. 


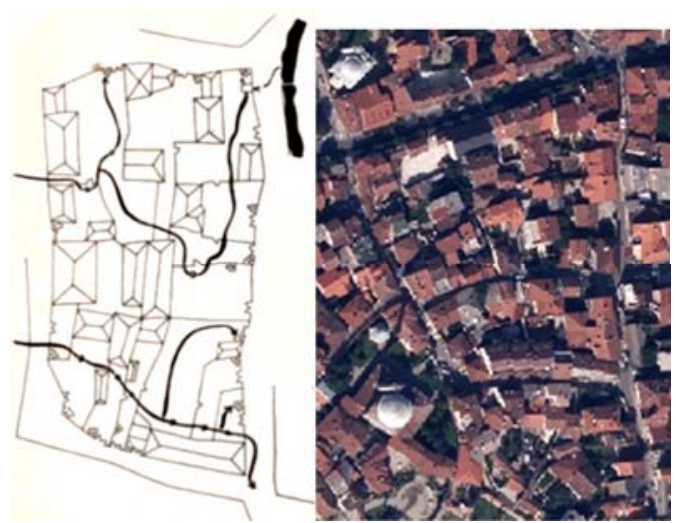

a)

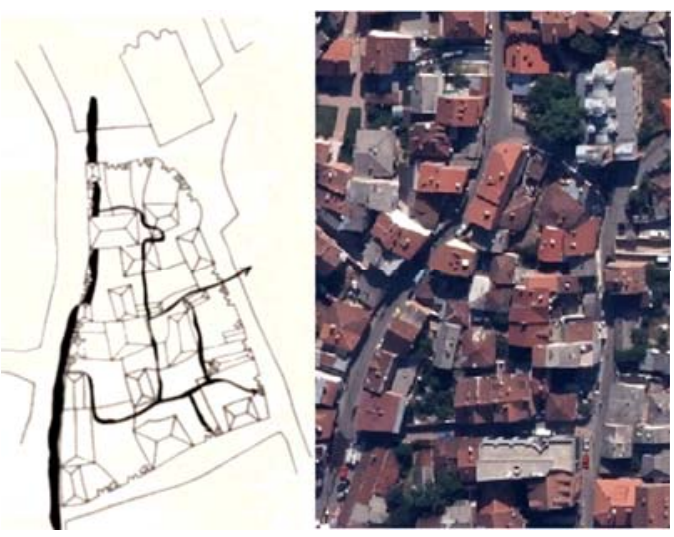

b)

Fig. 8. Scheme of the system of channels in the neighborhoods of the city,

a) Str. 'Ardian Zurnaxhiu' 1962 [19] and nowadays [16]

b) at Church 'Bogorodica Ljeviška' 1962 [19] and nowadays [16]

There is no evidence of the exact time of their creation; however it is supposed that they are created during Ottoman Era in an organic way as per local crafts and knowledge of the inhabitants of Prizren. These channels have been among the main features that have made the city of Prizren distinguished from the other cities of the region. In the beginning the primary function of these water channels was irrigation of the fields near the city of Prizren, supplying households with clean water for washing and drinking, and watering of the gardens. By the time these channels starting to play a very important role also in the social life of the city, holding many social activities alongside these channels. It especially played a very important role also in the environmental aspect, as the air refreshment factor of the city, creating a feeling of freshness, purity, and serenity, especially during the hot summer months. 


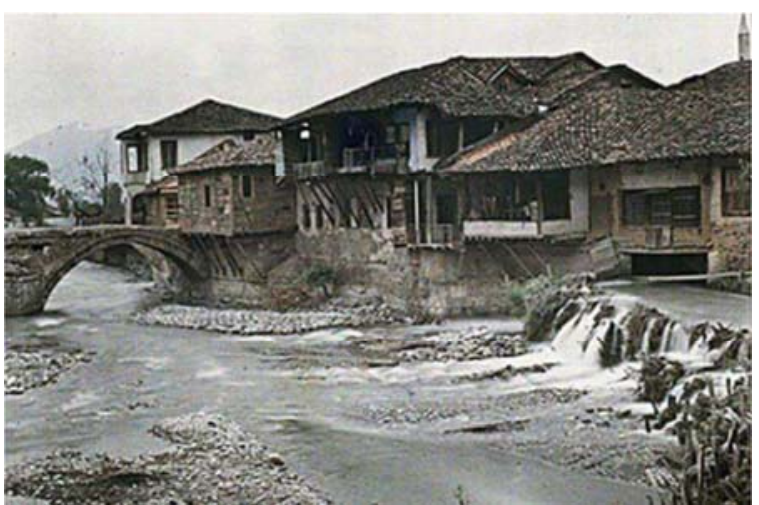

Fig. 9. Water return to the river, Albert Kahn 1913 [18]

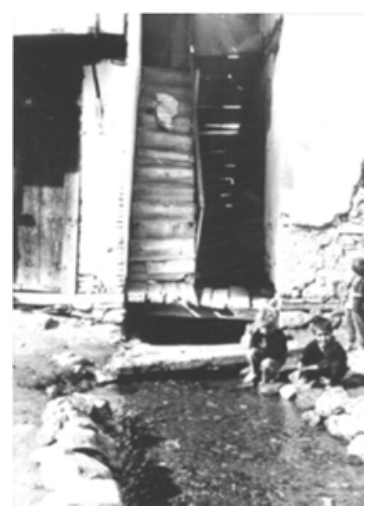

Fig. 10. Children standing and playing next to the 'Jaz' [18]

In the beginning a lot of families carried ducks as pets in these channels on public streets, thus creating a public attraction in the neighborhoods. However, with time, with the construction of the channels sides, this tradition of cultivation and treatment of the ducks as public attraction has come to wane gradually, Fig. 11.

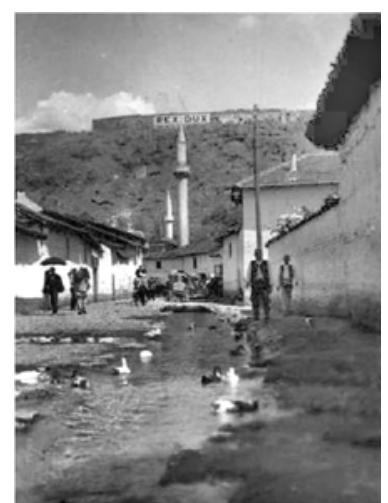

a)

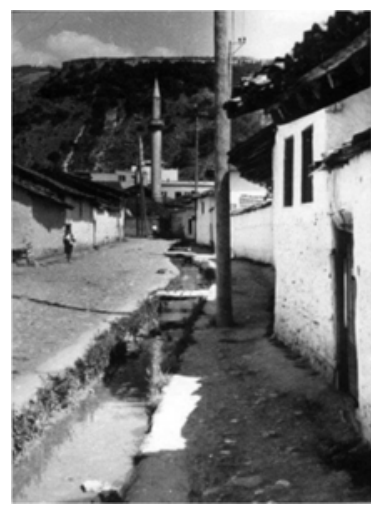

b)

Fig. 11. Kukli Beg 'Jaz' in the public streets; a) ducks swimming on the channel; b) after making the channels sides, [15]

These channels played a very important role also in the development of the trade of the city. On these channels were built mills, tanneries, coffee and tea houses, pastry shops, butchers, and other craft shops. They served to put into function over 35 mills of the city for grinding cereals, and mills for processing of wool and leather. Although the river was very small, it had a high-speed flow; the river was going down for $2000 \mathrm{~m}$ in less than 2 hours. Therefore through the energy from the river, it has been managed to put into the function these mills, see Fig. 12. 


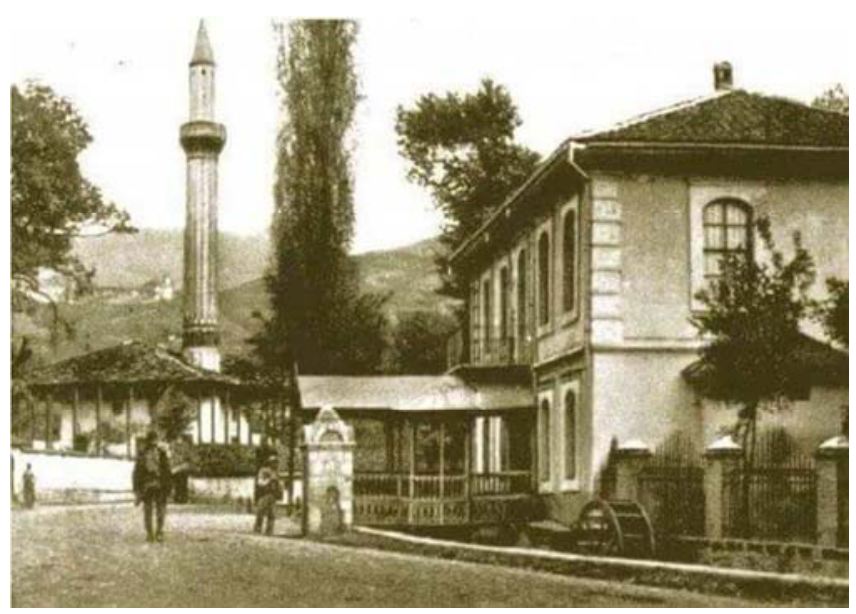

Fig. 12. Putting a mill into the function by the water channel, Albert Kahn 1913 [18]

During the Ottoman Era there were four main channels spreading from the river Bistrica. Three of them were on the right side, starting from Kasim Beg, Kugli Beg and Suzi Çelebi, and from the left side Beg Zade, as it is shown in Fig. 13. The largest part of the city was supplied by only two channels, one from the right side - Kukli Beg, which passed almost through the entire city, thereby supplying almost all houses, and another one from the left side - Beg Zade, while the two other channels were including a smaller area of the city and were used less for house gardens.

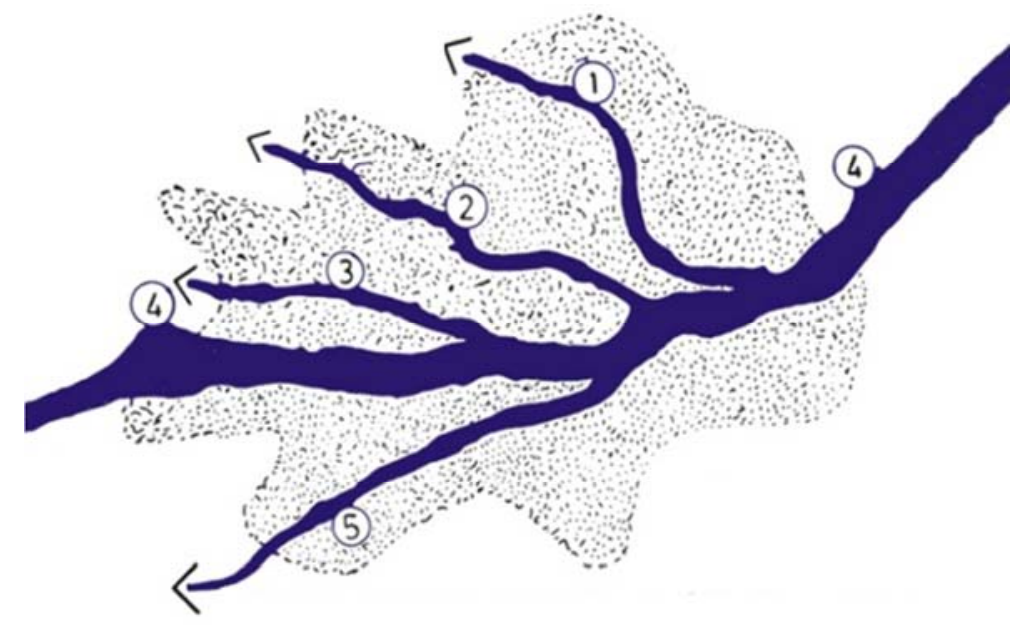

Fig. 13. Scheme of the main water channels, 1. Kasim Beg; 2. Kukli Beg; 3. Suzi Çelebi; 4. Bistrica River; 5. Beg Zade; [15] 
The channels were branched from river Bistrica by small dams, which were called 'bent'. These dams were neither high nor they had any special structure. These were usually small diagonal barriers made of stones installed conically, and their task was to direct the inflow of the water into the channels.

The dimensions of the main channels were about $100-200 \mathrm{~cm}$ width and $70-80 \mathrm{~cm}$ depth, while the smaller channels, which passed through the house gardens were about $40-50 \mathrm{~cm}$ width, and $25-35 \mathrm{~cm}$ depth [19], see Fig. 14.
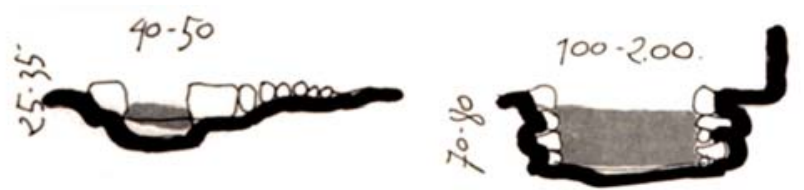

Fig. 14. Scheme of approximate dimensions of the channels, [19]

These channels were well constructed. The sides and bottom of them were lined with stone, so there was no excessive wastage of water. In every garden there was a smallish pool, in fact, less expansion in the channel, from which water was abstracted. The pool was so called 'kurna', and a stone funnel which brings water into the pool was called 'çepur' (Fig. 15 - Fig. 16). Both of them were of the same size and shape [19].

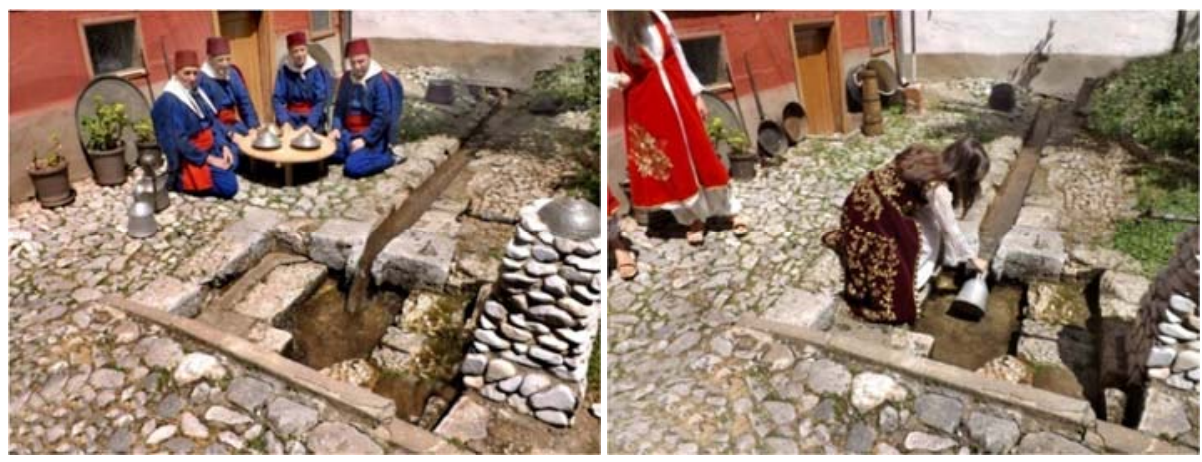

Fig. 15. 'Jaz', 'kurna' and 'çepur' in a house garden, [15]

\subsection{Destruction of the water channels}

After the World War II began there was a fast destruction of these water channels by the reign of the settlers from different places, who never realized the value of these channels for the city. They cut off all the branches of the river, so for the new generations were left only their old trunk. Moreover, they built the walls of the river by force and forever separated the river from the city. So they divided the neighborhoods from neighborhoods, neighbors from neighbors and the environment from the city. From the magic creation that used to be the inspiration, place for fun and love it turned to a half river and half sewage (Fig. 17). 

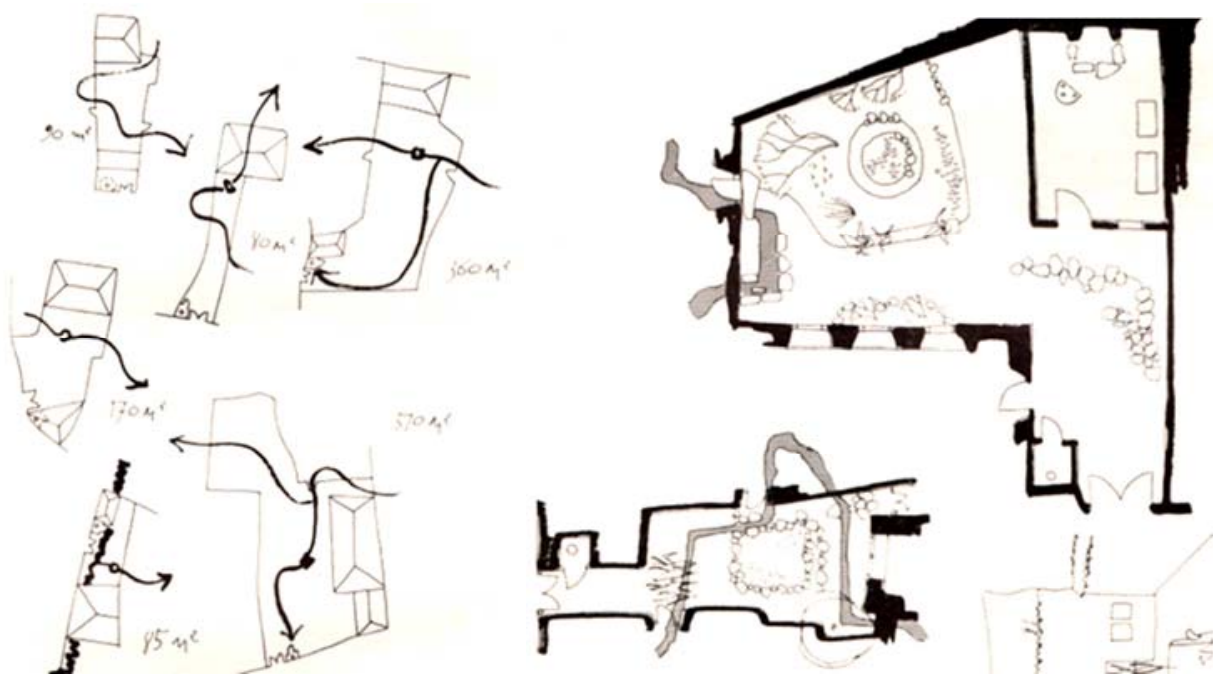

Fig. 16. Scheme of some gardens with positions of 'jaz', 'kurna' and 'çepur', [19]

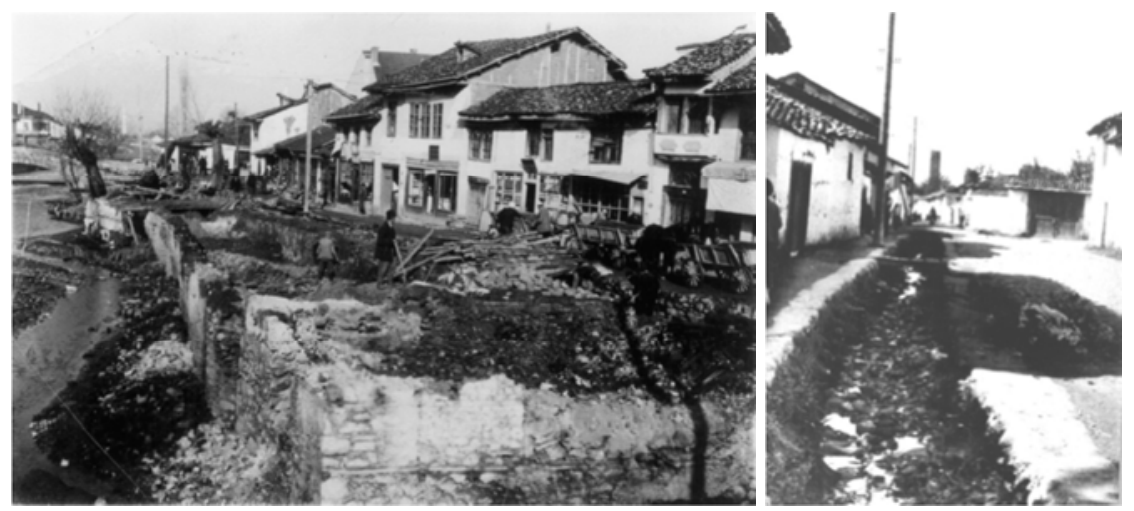

Fig. 17. Destruction of the water channels, [18]

\subsection{Current state of the water channels}

There are still remaining some of these channels, however they are not even similar to the system of channels that used to be and they do not act as an integral part of the system as it was before. All these are made as specific projects, not as a whole, more like improvised channels with standing water, and they are more like a source of wastewater, rather than as an integral part of the urban area. Even their dimensions, materials and the way they are implemented do not correspond with the nature, character and functions of the unique system of channels that used to be sometime (Fig. 18 - Fig. 19). 

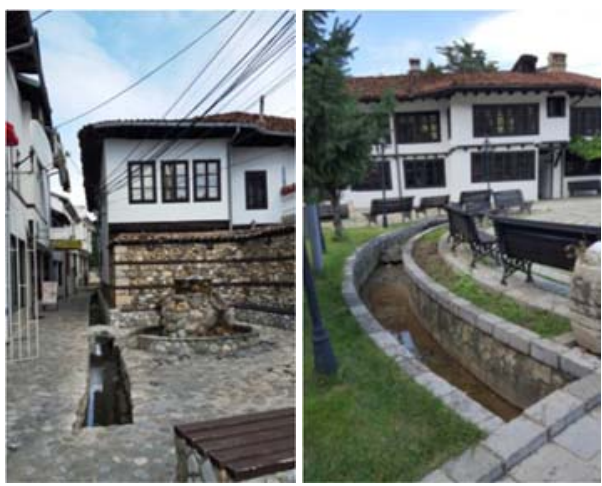

Fig. 18. Newly constructed water channels at the Albanian League of Prizren
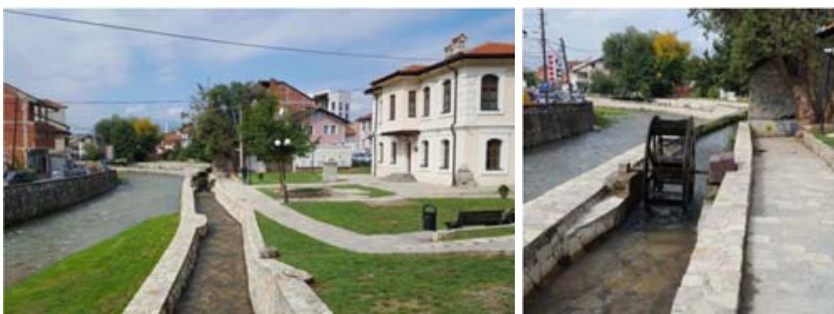

Fig. 19. Newly constructed water channels at the mill in the neighborhood Tabakhane

\section{Conclusions and recommendations}

This unique sophisticated system of water channels played a very important role in the urban area, which connected the city with the environment.

In the beginning it was raised the question if it is worth to functionalize and restore these water channels for the use of today's needs, and definitely the answer is yes, since the biggest benefit from rehabilitation of this unique system of water channels would have the citizens of Prizren in social, economic, spatial and environmental aspect.

Is it possible? There is no possibility to restore the entire system of the channels, due to the big number of new constructions, since it was spread all over the city, in every house of the city. However, there is a possibility to restore these channels partially in the Historic Zone, where still remain some parts of the channels.

This should be done only in the way that these channels be scattered from the river, and again return to the riverbed, the water should be flowing all the time, otherwise, only with the standing water they will return to the wastewater channels, as they are now.

Rehabilitation of the channels should be done with appropriate dimensions and local materials, in harmony with existing situation of the Historic Centre, in order to achieve a harmonious development of the historic city of Prizren. Further research needs to be done in order to find the best solutions for rehabilitation of this unique system of water channels, in cooperation between local and central institutions and the local community. 


\section{Acknowledgements}

This work has been undertaken as a part of a project founded by the Pollack Mihály Faculty of Engineering, University of Pécs.

\section{References}

[1] Ramlee M., Dasimah O., Yunus M. R., Samadi Z. Revitalization of urban public spaces, An overview, Procedia - Social and Behavioral Science, Vol. 201, 2015, pp. 360-367.

[2] Holland S. Revitalizing broadway east what does 'revitalizing' mean? Weaving, Policy, People and Places Together, http://www.mpnh.org/ ASSETS/DOCUMENT/WPPPT/ REVITALIZATION--\%20Working\%20Definition1.pdf, (last visited 20 December 2016).

[3] Topçu M., Kubat A. S. Old and new city: morphological analysis of Antakya, Proceedings on Eighth International Space Syntax Symposium, Santiago de Chile, 3-6 January 2012, pp. 8251-8251.

[4] Yee S. T., Yoh S. Rehabilitation methods and revitalization strategies in the old inner-city: Areas of rapid growth cities in Asia, A comparison of four cities: Penang, Hanoi, Shanghai and Tokyo, Proceedings of International Symposium on City Planning 2014, Hanoi, Vietnam, 6-8 November 2016, Urban and Regional Planning Review, Vol. 3, 2016, pp. 1-20.

[5] Rezazade M. H., Rad R. I., Hashemzehi F. Analyzing the revitalization strategies of historical fabric with the approach of endogenous development, Case Study $(1,2 \& 3$ Regional of Zahedan City), Open Journal of Geology, Vol. 6, No. 6, 2016, pp. 363-371.

[6] Li X., Lv Z., Hijazi I. H., Jiao H., Li L., Li K. Assessment of urban fabric for smart cities, IEEE Access, Vol. 4, 2016, pp. 373-382.

[7] Ozlati E., Nasr T. Regeneration of historical fabrics with the approach of mental image and memory of the places (Case study: Shiraz Historic Pathway 'Khaneghah Ahmadi'), European Online Journal of Natural and Social Sciences, Vol. 4, No. 3, 2015, pp. 356-368.

[8] Zoltan S. E. Office spaces for more innovation and space efficiency, Pollack Periodica, Vol. 9, No. 2, 2014, pp. 67-76.

[9] Juhász M. Assesing the requirements of urban traffic calming within the framework of sustainable urban mobility planning, Pollack Periodica, Vol. 9, No. 3, 2014, pp. 3-14.

[10] Prizren, Wikipedia, https://en.wikipedia.org/wiki/Prizren, (last visited 20 December 2016).

[11] Municipal profile - Prizren, June 2006, OSCE.

[12] Archive of statistical office of Kosovo, http://ask.rks-gov.net, (last visited 20 December 2016).

[13] https://en.wikipedia.org/wiki/Prizren, (last visited 20 December 2016).

[14] http://kingofwallpapers.com/prizren/img-008.php?pic=/prizren/prizren-008.jpg, (last visited 20 December 2016).

[15] Vırmiça R. Crafts, missing crafts and forgotten items in Kosovo-Prizren, (in Turkish), Tika, Prizren, 2014.

[16] http://geoportal.rks-gov.net/, (last visited 20 Decembet 2016).

[17] https://sbunker.net/teh/64885/tue-lype-qytetet-e-kosoves/, (last visited 20 December 2016)

[18] Archive of regional center for cultural heritage-Prizren, http://www.mkrsks.org/?page $=1,110$, (last visited 20 December 2016).

[19] Ranko F. About the old network of channels in Prizren and their protection, (in Serbian) Institut za zastitu spomenika kulture, Beograd, 1962. 